Article

\title{
Mineralization Content Alters Osteogenic Responses of Bone Marrow Stromal Cells on Hydroxyapatite/Polycaprolactone Composite Nanofiber Scaffolds
}

\author{
Timothy T. Ruckh ${ }^{1}$, Derek A. Carroll ${ }^{2}$, Justin R. Weaver ${ }^{3}$ and Ketul C. Popat ${ }^{1,2, *}$
}

1 School of Biomedical Engineering, Colorado State University, Fort Collins, CO 80523, USA; E-Mail: t.ruckh@neu.edu

2 Department of Mechanical Engineering, Colorado State University, Fort Collins, CO 80523, USA; E-Mail: dac376@cornell.edu

3 Department of Chemical Engineering, Colorado State University, Fort Collins, CO 80523, USA; E-Mail: jweaver@engr.colostate.edu

* Author to whom correspondence should be addressed; E-Mail: ketul.popat@colostate.edu; Tel.: +1-970-491-1468.

Received: 20 June 2012; in revised form: 25 September 2012 / Accepted: 24 October 2012 / Published: 14 November 2012

\begin{abstract}
Synthetic tissue scaffolds have a high potential impact for patients experiencing osteogenesis imperfecta. Using electrospinning, tissue scaffolds composed of hydroxyapatite/polycaprolactone (HAp/PCL) composite nanofibers were fabricated with two different HAp concentrations-1\% and $10 \%$ of the solid scaffold weight. After physico-chemical scaffold characterization, rat bone marrow stromal cells were cultured on the composite scaffolds in maintenance medium and then in osteogenic medium. Quantitative PCR, colorimetric assays, immunofluorescent labeling, and electron microscopy measured osteogenic cell responses to the HAp/PCL scaffolds. In maintenance conditions, both Hap/PCL scaffolds and control scaffolds supported cell colonization through seven days with minor differences. In osteogenic conditions, the $10 \%$ HAp scaffolds exhibited significantly increased ALP assay levels at week 3, consistent with previous reports. However, qPCR analysis demonstrated an overall decrease in bone matrix-associated genes on Hap/PCL scaffolds. Osteopontin and osteocalcin immunofluorescent microscopy revealed a trend that both mineralized scaffolds had greater amounts of both proteins, though qPCR results indicated the opposite trend for osteopontin. Additionally, type I collagen expression decreased on HAp scaffolds. These results indicate that cells are
\end{abstract}


sensitive to minor changes in mineral content within nanofibers, even at just $1 \% \mathrm{w} / \mathrm{w}$, and elucidating the sensing mechanism may lead to optimized osteogenic scaffold designs.

Keywords: nanofiber; scaffold; bone; hydroxyapatite; gene expression

\section{Introduction}

Bone tissue engineering remains a highly active area of research largely because of complications associated with challenging healing scenarios [1]. Synthetic tissue scaffolds for bone regeneration have taken several design approaches with the intent of enhancing bone formation by marrow stromal cells (MSCs) that migrate to the injury site. MSCs contain a heterogeneous cell population within which exist progenitor cells capable of differentiating into multiple phenotypes including osteoblasts [2-5]. In order to direct progenitor cell differentiation, biomimetic designs have aimed to create conditions and signals that would be found in actively remodeling bone tissue. Soluble signals such as growth factors or cytokines have been shown to enhance osteoblastogenesis [6-9] by activating cell surface receptors. Additionally, immobilizing and presenting extracellular matrix (ECM) proteins such as fibronectin and collagen or short adhesion peptides such as RGS have been shown to enhance proliferation and phenotypic behaviors of MSCs [10,11]. Micro- and nanotopographies have also been shown to modulate cell behaviors on metallic [12-14] as well as polymeric implant materials [15]. Previous studies have shown modestly enhanced osteoblast phenotypic behaviors by incorporating hydroxyapatite (HAp), a major constituent of the bone matrix, or other calcium phosphate phases in the bulk of the scaffolds $[16,17]$. To date, only one investigation with polymer-mineral composite nanofibers has described osteoblast behaviors beyond ALP enzymatic activity and Ca-P neo-mineralization [17-19].

Electrospinning has become very popular technique within the tissue engineering community because it can consistently produce polymer fiber scaffolds with diameters ranging from less than $100 \mathrm{~nm}$ up to several microns [20]. Under a high electric potential, a Taylor cone of polymer solution forms at the catheter tip. Once the electrostatic forces overcome the viscosity and surface tension, a polymer jet is ejected and it travels from the catheter to a grounded collector positioned nearby with a trajectory that follows the electric potential field lines. As the jet travels, the polymer solvent evaporates, leading to the deposition of very fine fibers on the grounded collector [20-22]. In this study, we have fabricated hydroxyapatite/polycaprolactone (HAp/PCL) composite nanofiber scaffolds by electrospinning to examine key changes in osteoblast phenotypic behavior. PCL is a semi-crystalline, biocompatible, aliphatic polyester [23] that has been frequently utilized for tissue engineering applications over the past 10-15 years. It is biodegradable, with a relatively slow degradation rate [24], and its non-acidic degradation pathways add to its appeal in biological applications [25]. As a result, it is generally regarded as a compatible scaffold material for both hard and soft tissues $[16,26]$.

Hydroxyapatite $\left(\mathrm{Ca}_{5}\left(\mathrm{PO}_{4}\right)_{3} \mathrm{OH}\right)$ (HAp) is the primary inorganic phase of bone tissue, and in Haversian bone it resides in gaps at the ends of type I collagen fibrils with a well-controlled crystallographic orientation [27]. As new bone is forming and existing bone is remodeling, osteoblasts secrete bone matrix vesicles (BMVs) containing $\mathrm{Ca}^{2+}$-rich fluid and phosphatases such as alkaline phosphatase (ALP) $[28,29]$. HAp integration into type I collagen comprises a bone subunit, and mature 
bone tissue is further strengthened by its hierarchical architecture [30-32]. Cells are capable of binding to collagen through several integrin heterodimers [33], but binding to HAp crystals is believed to require adaptive proteins, notably osteopontin [34-36]. Because HAp is an important component of natural bone tissue, it is an attractive design feature for synthetic bone tissue scaffolds as a means of more closely mimicking the natural tissue composition [17,18,37-40]. Thus, using the electrospinning technique, we have fabricated HAp/PCL composite nanofiber scaffolds with varying amounts of HAp.

The overall aim of this study was to determine the effect of HAp concentration in randomly oriented HAp/PCL nanofibers on key osteoblast behaviors and bone matrix production. PCL nanofiber scaffolds with two different concentrations of HAp nanoparticles were fabricated by the electrospinning process, thus creating HAp/PCL composite nanofibers. The HAp nanoparticles are attractive because they can be incorporated into the nanofiber architecture during electrospinning without disrupting the nanofibrous architecture. In order to account for the effects of electrospinning on PCL properties and nanoarchitecture on cells, control scaffolds were fabricated without any HAp nanoparticles under similar conditions as the HAp/PCL composite scaffolds. The effects of different HAp concentrations in HAp/PCL composite scaffolds were examined with MSCs cultured in maintenance media through 7 days, and then in osteogenic media for 3 weeks.

\section{Results and Discussion}

\subsection{Fabrication and Characterization of HAp/PCL Composite Nanofiber Scaffolds}

This study aimed to determine the effects of HAp nanoparticles in polymer-mineral composite nanofiber scaffolds for bone regeneration. In order to assess the effects of HAp nanoparticles, scaffolds were fabricated with $1 \%$ or $10 \% \mathrm{w} / \mathrm{w}$ HAp nanoparticles, and HAp-free scaffolds were used as a control treatment. Prior research demonstrated that HAp nanoparticles can integrate into polymer nanofibers; however studies that did not use a surfactant reported HAp particle agglomeration [19]. Similar prior research with polyester/hydroxyapatite composite nanofibers has also shown that adding hydroxyapatite nanoparticles to the electrospinning solution does not have a significant effect on water contact angle [41]. To prevent agglomeration of hydrophilic HAp nanoparticles in the electrospinning solution with organic solvents and hydrophobic PCL, oleic acid (OLA) was used as a surfactant. Low-magnification SEM images showed no large-scale HAp particle agglomeration, and high-magnification images with EDX spectral scans verified that HAp particles are dispersed randomly within PCL nanofibers in both 1\% HAp and 10\% HAp scaffolds (Figure 1A-C). There was a small, measurable decrease in the mean fiber diameter for scaffolds with 10\% HAp (Figure 2), from 371 to $293 \mathrm{~nm}$. However, for all three scaffold types, $>80 \%$ of the fibers measured within 200-600 nm in diameter (Figure 2). EDX spectral maps for both types of HAp/PCL composite scaffolds show a difference between the signal from gold-coated surface fibers (Figure 1D and E, bottom images and spectra for each) and the signal from the uncoated interior fibers (Figure 1D and E, top images and spectra for each). Both spectral maps show the presence of calcium and phosphorus, but only the surface spectra show gold. Additionally, the homogenous appearance of spectral maps support the observation that HAp nanoparticles did not agglomerate and cause breaks in the polymer nanofibers. 
Figure 1. SEM (A-E) and EDX (F-I) images and spectra for PCL scaffolds with $0 \%(\mathbf{A}) 1 \%$ $(\mathbf{B}, \mathbf{D}, \mathbf{F}, \mathbf{H})$ or $10 \%(\mathbf{C}, \mathbf{E}, \mathbf{G}, \mathbf{I})$ HAp nanoparticles. Top image is SEM, middle image is EDX spectral image of non-surface nanofibers (no Au coating), and bottom image is EDX spectral image of surface nanofibers (Au coating). All images were taken at 1000× magnification.

HAp-free

$1 \%$ HAp

$10 \%$ HAp
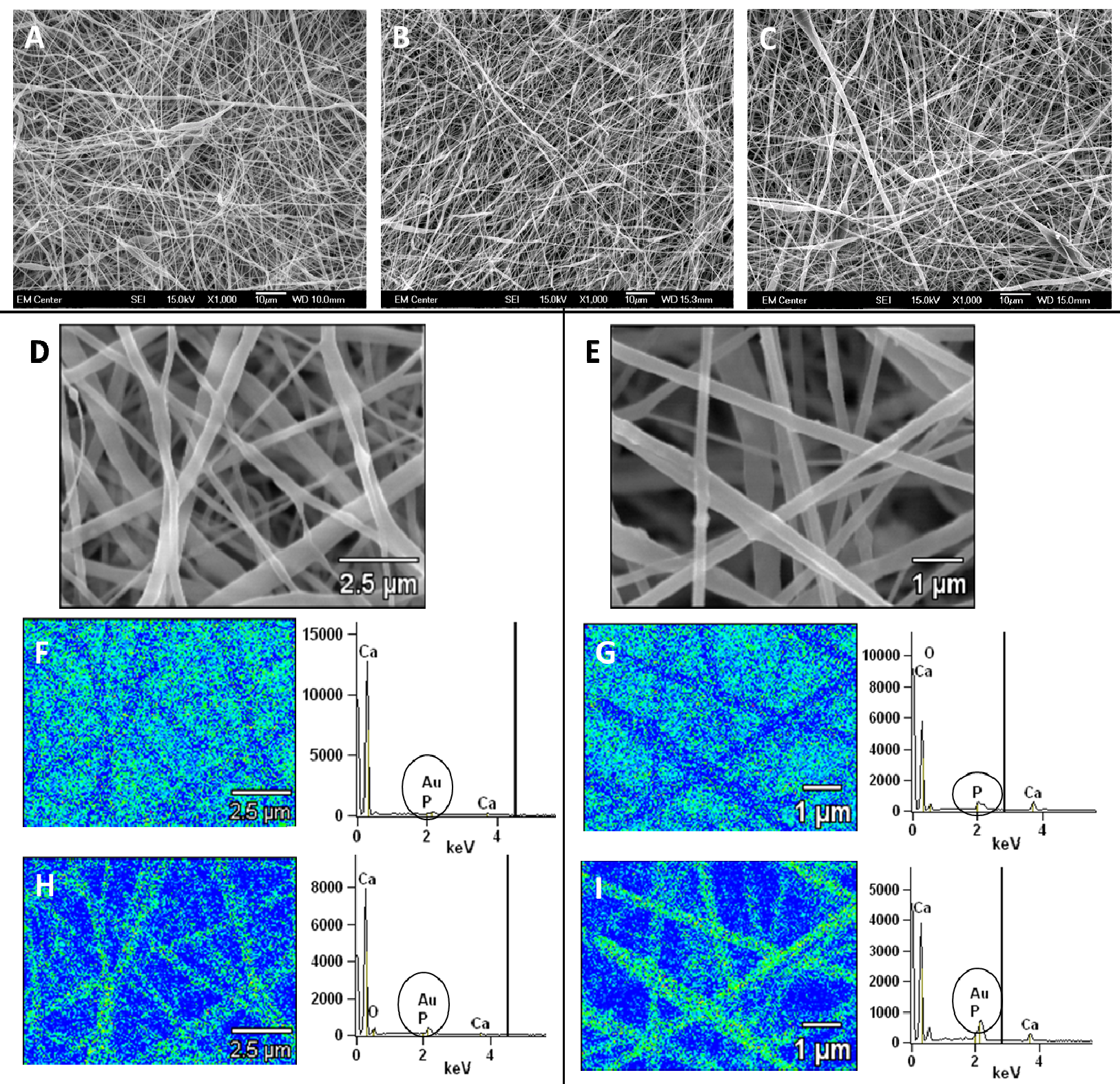
Figure 2. Fiber diameter histogram showing the scatter for measured fiber diameters, the $95 \%$ confidence intervals, mean fiber diameter values, and standard deviations for each of the three scaffolds.

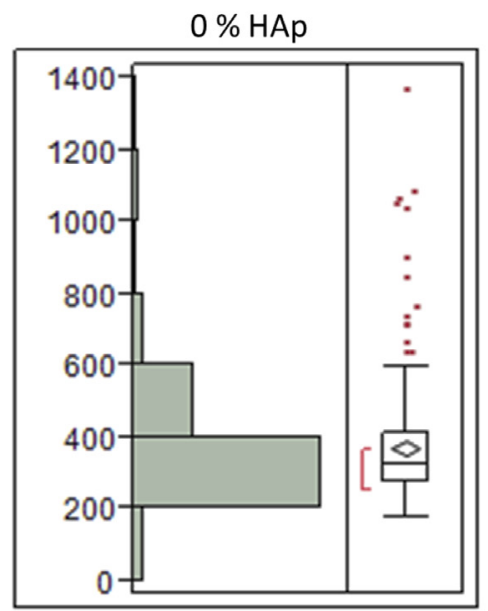

Mean : $371 \mathrm{~nm}$ Std. Dev: $170 \mathrm{~nm}$ 95\% Cl mean: $349-394 \mathrm{~nm}$

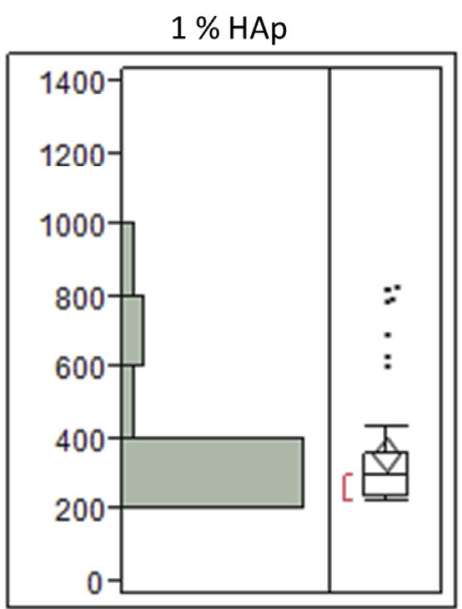

Mean : $358 \mathrm{~nm}$

Std. Dev: $176 \mathrm{~nm}$

95\% Cl mean: $309-406 \mathrm{~nm}$

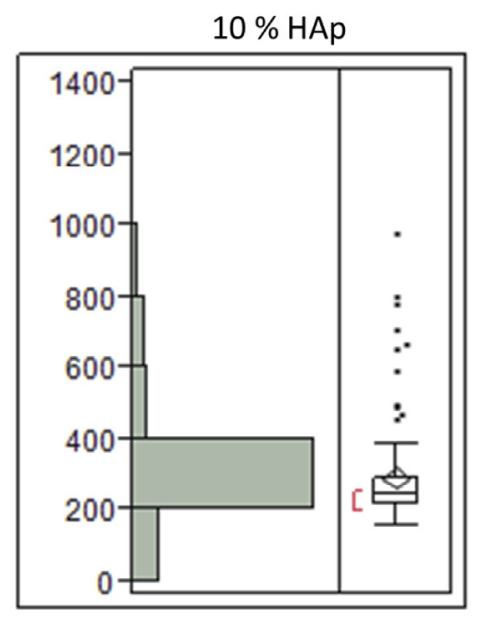

Mean : $293 \mathrm{~nm}$ Std. Dev: $152 \mathrm{~nm}$

$95 \% \mathrm{Cl}$ mean: $260-325 \mathrm{~nm}$

Effect of HAp on fiber diameter: $p=0.0002$

Previously, 12-hydroxystearic acid was effective in preventing HAp agglomeration in polymer-mineral composite nanofiber scaffolds [42]. This approach of adding a fatty acid may contribute to the consistency of fiber diameter characteristics between scaffolds with varying HAp concentrations. It is important to note that although the mode was consistent across all three scaffolds, the population characteristics were different and are reflected in the $95 \%$ confidence intervals and in the overall main effect being highly significant (Figure 2). In this study, we chose OLA because it is non-toxic and may serve as an additional osteogenic design factor by activating fatty acid receptors. It is a known agonist to peroxisome proliferator-activator receptors (PPARs), a class of nuclear receptors [43-45]. PPARs affect transcriptional regulation for a wide range of cellular functions and processes, and agonists for the isoform PPAR have been shown to enhance osteoblastogenesis markers [46-49]. In order to account for possible effects of OLA as a PPAR agonist, the concentration as held constant for all scaffolds.

Thermal gravimetric analysis (TGA) and digital scanning calorimetry (DSC) were used to measure the composition and crystallinity of the HAp/PCL composite nanofiber scaffolds. Source PCL (not electrospun) was included to detect any changes to the polymer crystallinity due to the electrospinning process and/or HAp nanoparticles. DSC results (Figure 3A) showed that HAp did not significantly change PCL crystallinity. The percent mass loss due to PCL degradation measured by TGA was significant different between 10\% HAp scaffolds and all other samples (Figure 3B), and that difference was approximately $10 \%$ of the sample mass. The differences between $1 \%$ HAp and $0 \%$ HAp (control) scaffolds were too small to be statistically significant in a t-test, although the ANOVA model determined that the effect of HAp on $\%$ mass loss was highly significant $(p=0.001)$. The differences in composition between HAp-free and 1\% HAp scaffolds were too small to produce statistical significance, but both scaffolds were significantly different from 10\% HAp scaffolds, and EDX confirmed the presence of Ca-P in the $1 \%$ HAp scaffolds. 
Figure 3. Thermal characterization with (A) the \% crystallinity and (B) mass loss measured by DSC and Thermogravimetric analysis (TGA), respectively. Each treatment $(0,1$, or $10 \%$ HAp) was measured as well as the source PCL, which was not processed by electrospinning. A $\&$ indicates statistically significant difference $\left(\mathrm{p}_{\text {crit }}=0.05\right)$.

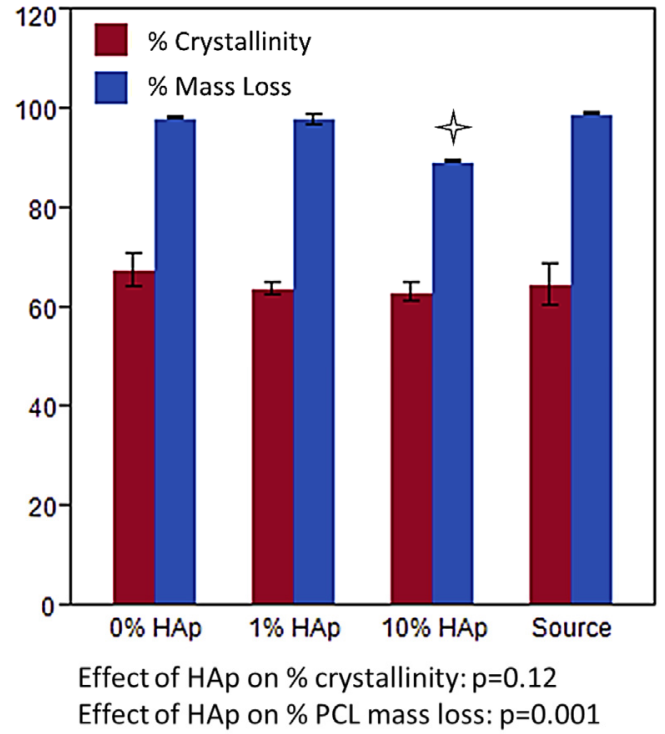

(A)

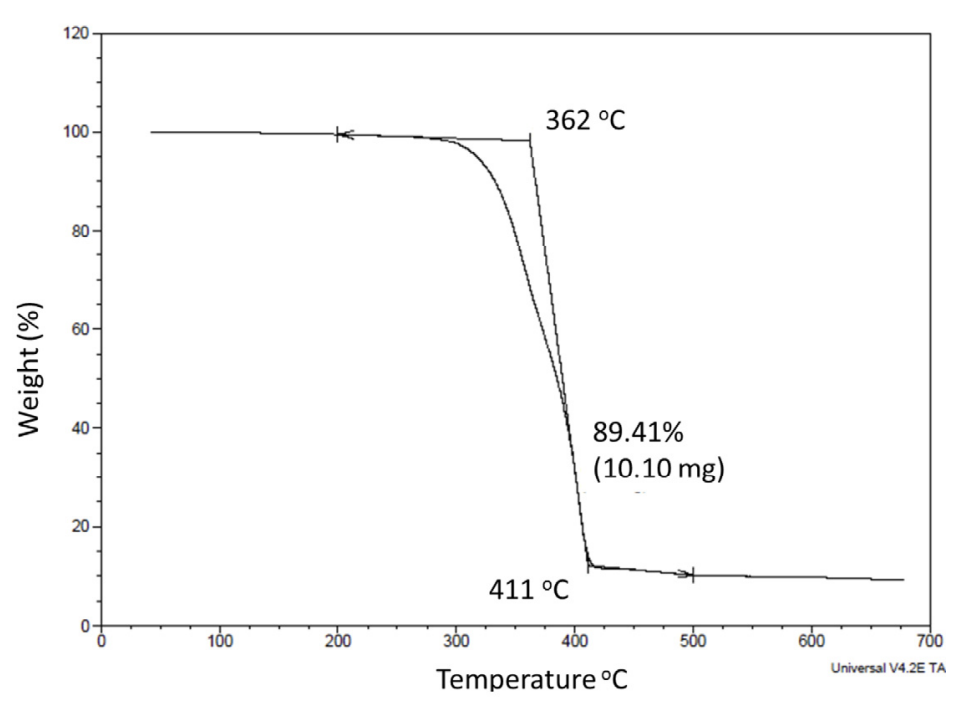

(B)

Taken together, the SEM/EDX images combined with TGA and DSC data provided strong evidence that HAp nanoparticles are smoothly incorporated into the PCL nanofibers at the desired concentrations of $1 \%$ and $10 \% \mathrm{w} / \mathrm{w}$. The statistically significant differences in fiber diameter measured by SEM represented a change of $\sim 80 \mathrm{~nm}$ (Figure 2), and the fiber diameter histograms showed that all three scaffolds have $>80 \%$ of their fibers in the same diameter range of $200-400 \mathrm{~nm}$. These differences were within a range of fiber diameters that have been shown to have negligible influences on osteoblasts as well as fibroblasts, a phenotype sharing a very similar transcriptome to that of osteoblasts [50], cultured on nanostructured polymer materials [51,52]. Due to the relatively small changes to fiber diameter and the relative insensitivity of these cells to those small changes, it is reasonable to assume that the differences in fiber diameter are unlikely to influence the cellular responses. Any differences in cell behaviors between the scaffolds are more likely a consequence of variations in HAp concentration.

\subsection{MSC Response to HAp/PCL Composite Nanofiber Scaffolds in Maintenance Conditions}

Fracture repair entails multiple overlapping healing phases involving wide range of processes for cell recruitment and signaling [53-55], ECM production [56-59], and then continual ECM remodeling [60-62]. Fundamental to each of these processes is the ability for cells to adhere and proliferate in the repair area. Calcein AM is a cell-permeable fluorescent stain that is only retained by live cells when esterases cleave the AM group, leaving the impermeable calcein molecule in the cytoplasm. By imaging live cells with calcein AM fluorescent stain, measuring their coverage area, and measuring metabolic activity with an MTT assay, cell adhesion and colonization can be evaluated. For the first seven days after seeding fresh rat bone marrow stromal cells onto scaffolds the cells were 
cultured in maintenance media free of differentiation factors to allow for the heterogeneous marrow stromal population to populate the scaffold. An MTT assay measured the overall metabolic activity on PCL/HAp scaffolds, and he overall effect of scaffold HAp content was not significant $(p=0.356)$. However, the interaction effect of Hap*day, meaning the change on each scaffold between days, was highly significant $(\mathrm{p}=0.0031)$, with $10 \%$ HAp scaffolds causing a decrease between days one and four and $0 \%$ and $1 \%$ scaffolds causing very small changes in metabolic activity (Figure 4).

Figure 4. (3-[4,5-dimethylthiazol-2-yl]-2,5-diphenyl tetrazolium bromide (MTT) assay values for days 1 and 4 . MTT values measured on each scaffold $(0,1$, or $10 \%$ HAp) are grouped within each day. Bar graph shows daily data, with a $\not$ indicating a statistically significant difference $\left(\mathrm{p}_{\text {crit }}=0.05\right)$ from other treatments within the timepoint. An ANOVA analysis is summarized with F-statistics and p-values for the effects of HAp, day, and the interaction of HAp and day.

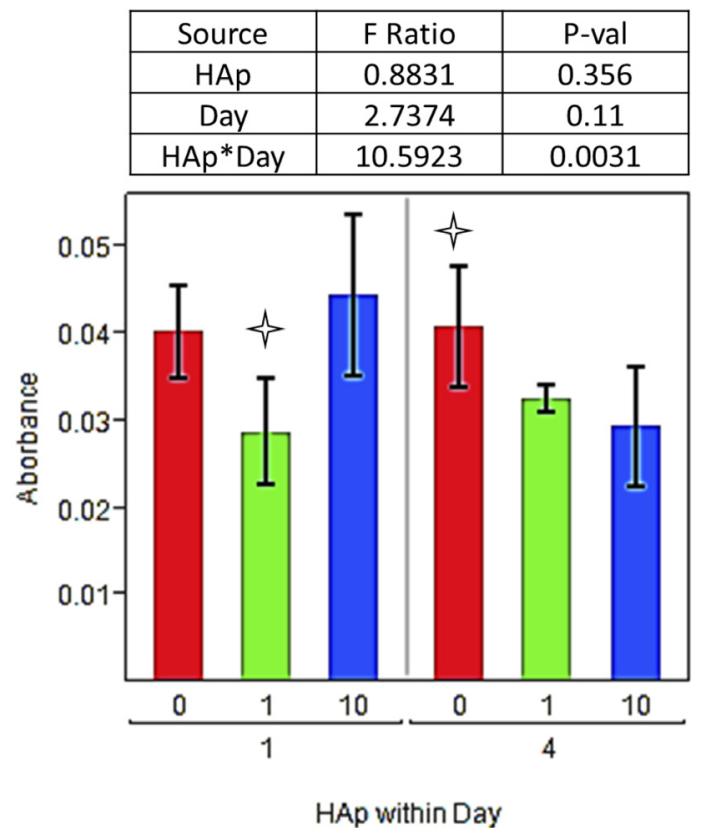

Metabolic expenditures during the first days of cell seeding are likely to go towards cell proliferation, though the fluorescence microscopy images (Figure 5) demonstrate that substantial cell spreading occurred (cytoskeletal formation and reorganization) during the first week. The ANOVA of cell coverage, calculated from calcein-AM live cell images (Figure 5) shows that HAp also did not significant affect $(\mathrm{p}=0.38)$ cell coverage, although individual t-tests within days one and four revealed that cells on $0 \%$ HAp scaffolds were significant different from cells on scaffolds containing either $1 \%$ or $10 \%$ HAp. Although $0 \%$ HAp scaffolds supported the lowest cell coverage on day 1 , the MTT assay measure a relatively high level of metabolic activity, which may explain why those scaffolds supported significantly greater cell coverage on day 4 . More importantly though, after seven days in culture, the cells on all three scaffolds had densely populated the scaffolds' surfaces, and there were no significant differences in cell coverage.

Although there were differences in both MTT and cell coverage at days one and four, cell coverage was nearly equal by day seven and the overall effect calculated by the ANOVA model do not meet significance at a $95 \%$ confidence level. Thus we reason that the cell populations were very similar at 
day seven, when differentiation factors were added to the culture. This is consistent with recent literature examining nanofiber scaffolds containing HAp nanoparticles [18].

Figure 5. Fluorescent images (A) of live cells stained with Calcein AM on HAp-free $(0 \%$ HAp), 1\% HAp, and 10\% HAp scaffolds at days 1, 4, and 7 post-seeding. Zoom $=10 \times$, scale bar $=50 \mathrm{~mm}$ on each image; Quantitative cell coverage data (B) from calcein AM fluorescent images is grouped so that each treatment $(0,1$, or $10 \% \mathrm{HAp})$ is contained within the day $(1,4$, or 7$)$ on which the measurements were taken. Bar graph shows daily data, with a $\&$ indicating statistically significant difference $\left(\mathrm{p}_{\text {crit }}=0.05\right)$ from other treatments. An ANOVA summary is presented with F-statistics and p-values for the effects of HAp, time (day), and the interaction of HAp and time.

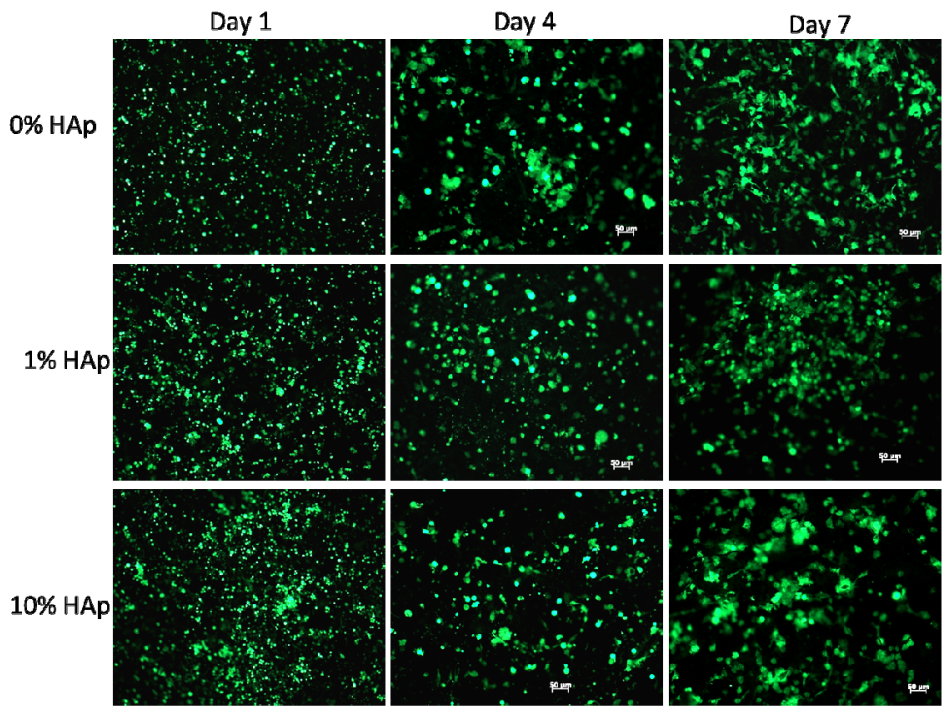

(A)

\begin{tabular}{|c|c|c|}
\hline Source & F Ratio & P-val \\
\hline HAp & 0.80 & 0.38 \\
\hline Day & 0.79 & 0.38 \\
\hline HAp*Day & 2.15 & 0.15 \\
\hline
\end{tabular}

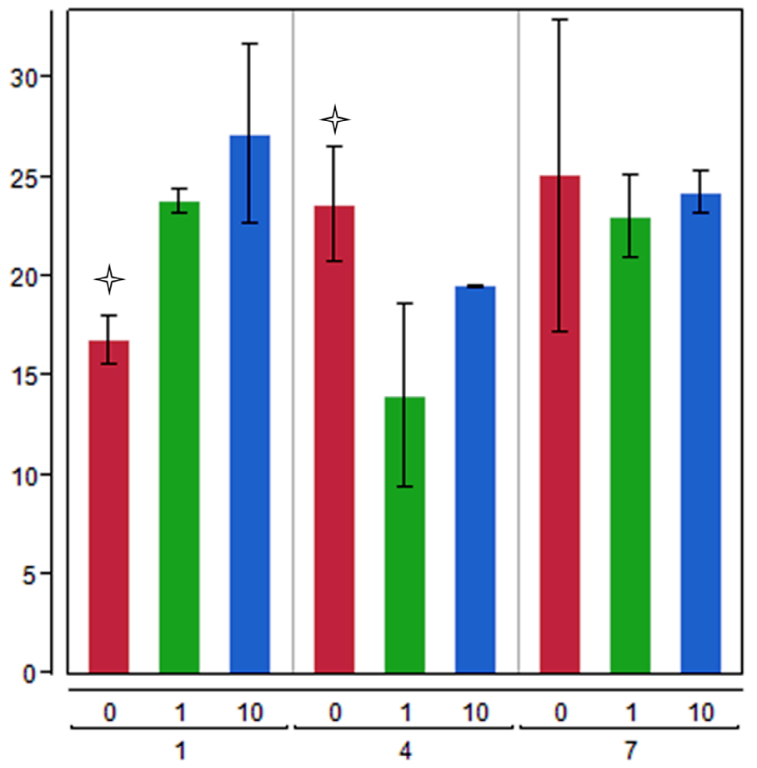

(B) 


\subsection{MSC Differentiation on HAp/PCL Composite Nanofiber Scaffolds}

Having established similar scaffold morphologies and similar MSC populations on all three scaffolds, the primary aim of evaluating osteogenic behaviors could be addressed. In order to evaluate the effects of Hap concentration on MSCs in osteogenic medium, a normalized colorimetric ALP assay along with normalized qPCR for five key genes were used. After three weeks in osteogenic medium, cells were also immunolabeled for two bone matrix proteins, OP and OC.

Alkaline phosphatase (ALP) is a key enzyme in bone matrix vesicles that cleaves organic phosphate esters, thus supplying mineral nucleation sites with free phosphate ions [28,63,64]. Its expression profile is typically associated with a peak during early differentiation of progenitor cells into immature osteoblast phenotypes, and then production tapers off as osteoblast cells either mature into osteocytes or undergo apoptosis [65]. As that maturation occurs, osteocalcin (OC) expression typically increases, indicating a late-osteoblast state. The ANOVA model for ALP determined that the overall effect of HAp was not significant $(\mathrm{p}=0.425)$, although the effect of changes between weeks was highly significant $(p<0.0001)$. The dynamic nature of ALP activity in immature osteoblasts may have dominated the ANOVA model. Normalized intracellular ALP activity on all three scaffolds after one week of culture was much lower than the following two weeks (Figure 6). After two weeks in osteogenic conditions, all three scaffolds supported substantial increases in ALP activity, although there were no significant differences within the time point. After three weeks of culture, the cells on $10 \%$ HAp produced significantly more ALP than the cells on HAp-free scaffolds, however, neither level was significantly different from $1 \%$ HAp scaffolds.

The final time point, after three weeks, shows that ALP is most abundant on $10 \%$ HAp scaffolds, and the difference between ALP levels on 10\% HAp and HAp-free scaffolds was significant. With ALP activity still high, and qPCR showing that OC expression levels were steady, this suggests that osteoblasts are still relatively immature after three weeks. This may be a consequence of the nanofiber morphology, as our previous work showed prolonged ALP activity on nanofiber scaffolds relative to smooth surfaces in the same culture conditions [15].

With regards to the modest increase in ALP activity on polymer-mineral composite scaffolds, other studies using different cell populations (hFOB or human MSCs) also found a similar trend of small increases in ALP activity on mineralized scaffolds [17,18,66,67]. Since these studies used different cell populations and a variety of mineralization levels but yielded similar results, this nominal increase in ALP activity through three weeks on synthetic HAp/PCL composite nanofiber scaffolds can be considered an acceptable and expectable result for in vitro studies.

Quantitative polymerase chain reaction (qPCR) was used to precisely measure the levels of gene expression for five key genes related to osteoblast behaviors: osteopontin (OP), osteocalcin (OC), type I collagen (ColI), RhoA, and casein kinase II (CKII). The expression level for each gene was normalized with respect to RPL13A, a housekeeping gene that encodes for the $60 \mathrm{~s}$ ribosomal subunit protein, L13A. Three of the five genes in the qPCR analysis were differentially expressed at significant levels due to HAp concentration within PCL scaffolds-OP $(p=0.0324)$, CKII $(p<0.001)$, and ColI $(p=0.0105)$. Of these, OP ${ }^{34,43,48}$ and ColI are bone matrix proteins while CKII is the enzyme believed to be primarily responsible for phosphorylating OP [68-70]. For all three genes, the overall 
effect was a decrease in expression when HAp concentration was increased in scaffolds which was largely driven by differences in week three (Figure 7).

Figure 6. Intracellular alkaline phosphatase (ALP) activity measured by colorimetric assay at weeks 1, 2 and 3. Each measurement was normalized for total protein, as assayed by the BCA method. Bar graph shows data with each HAp level $(0,1$, or $10 \%)$ grouped within the week $(1,2$, or 3$)$ when the measurement was taken. A $\ngtr$ indicates a statistically significant $\left(\mathrm{p}_{\text {crit }}=0.05\right)$ difference from other treatments. An ANOVA analysis is presented with F-statistics and p-values for the effects of HAp, week, and the interaction of HAp and week.

\begin{tabular}{|c|c|c|}
\hline Source & F Ratio & P-val \\
\hline HAp & 0.5884 & 0.425 \\
\hline Week & 151.5019 & $<.0001$ \\
\hline HAp*Week & 1.0844 & 0.280 \\
\hline
\end{tabular}

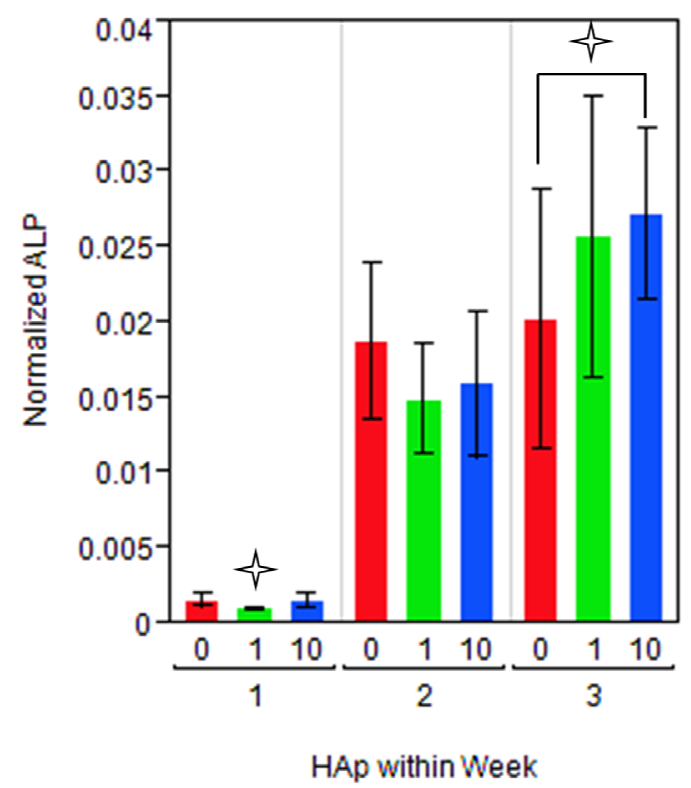

Collagen I (ColI) and osteopontin (OP) are both organic components of bone tissue. Both proteins are expressed by osteoprogenitors, pre-osteoblasts and osteoblasts, though OP is expressed in high levels across multiple phases of differentiation. ColI expression is similar to ALP in that they are both expressed highest by matrix-producing osteoblasts and then down-regulated as the cells mature into osteocytes [71]. In bone tissue, Coll comprises the major organic phase of bone, making up roughly $30 \%$ of bone mass, and it also provides integrin binding sites for cells. Bone matrix proteins such as $\mathrm{OP}$, osteonectin $(\mathrm{ON})$, and osteocalcin (OC) all play roles in regulating the manner with which ColI is integrated with HAp crystals in natural bone matrix [72-74].

OP is part of the family of non-collagenous proteins (NCPs) referred to as SIBLING (Small Integrin-Binding LIgand, N-Linked Glycoprotein) proteins [75]. It contains approximately 30 serine residues, depending on the species, and the degree of phosphorylation has been shown to regulate the exposure or obstruction of specific integrin binding sequences [34,35]. Like ColI, the main effect of HAp on OP expression levels was a significant $(\mathrm{p}=0.0324)$ overall decrease in expression. Using this overall, main effect to measure OP (and also ColI) is meaningful because both proteins would be 
synthesized and then secreted into the extracellular matrix. Thus the overall expression is a representation of the anticipated accumulation of either protein.

Figure 7. Normalized Collagen I (green), Osteopontin (red), RhoA (light blue), CKII (orange) and Osteocalcin (dark blue) expression measured by qPCR at weeks 1, 2, and 3. Each HAp level $(0,1$, or $10 \%)$ is grouped within a week $(1,2$, or 3$)$ so that comparisons are made between treatments and within time points. Each gene was normalized with respect to the copies of RPL13A. A $f$ indicates a statistically significance $\left(p_{\text {crit }}=0.05\right)$ difference from another treatment within the time point. An ANOVA adjusted for multiple comparisons analyzed the effects of HAp, week, and the interaction of HAp by week, and the F-statistics and p-values are summarized for each gene separately.
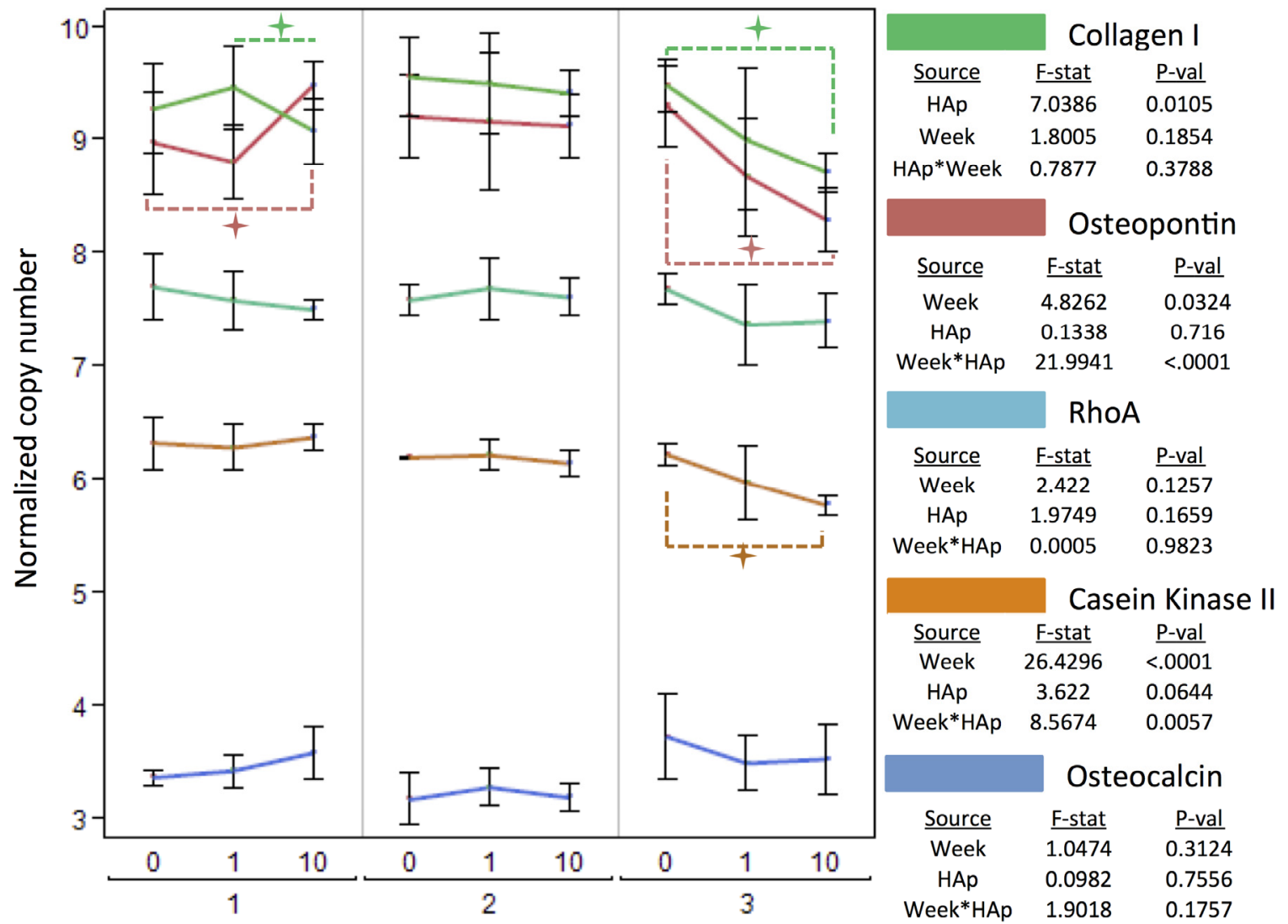

HAp within week

Casein Kinase II (CKII) is an intracellular serine/threonine kinase that is believed to be responsible for most of the physiologically relevant phosphorylation for bone phosphoproteins such as OP [68]. It phosphorylates serine residues, and the degree of phosphorylation of bone matrix proteins such as OP is believed to up or down-regulate local bone remodeling behavior by osteoblasts and osteoclasts $[35,76]$. Differences in OP phosphorylation would potentially be a cellular adaptation to changes in scaffold HAp concentration. The relative OP:CKII the expression ratio does move significantly differently between weeks (Figure 8). The differences are quite small, ranging from 1.4 to 1.5, but OP phosphorylation and the amount of OP present in the extracellular environment are believed to be potent contributors to controlling of neo-mineralization [34,35,68,77-81]. These results do not deliver a definite conclusion on the point, but they are worth noting. The unexpected results from qPCR were that ColI, OP, and 
CKII expression levels decreased in response to increasing the HAp content in nanofiber scaffolds except for one point, week one on $10 \%$ HAp scaffolds. A duplicate trial with a separate cell source produced the same trend, which validated this finding.

Because OP is a target substrate for CKII, the ratio of OP: CKII was also calculated and analyzed in an ANOVA, and only the interaction effect of HAp*week was significant $(p=0.0225)$. Figure 8 illustrates this parameter's physical meaning, showing a general increase in OP:CKII on 0\% HAp scaffolds from week one to week three. Conversely cells on 1\% HAp scaffolds peaked at week their OP:CKII expression at week two before showing a decrease, and cells on 10\% HAp scaffolds were relatively constant in their OP:CKII expression levels.

Figure 8. The ratio of osteopontin (OP): CKII calculated and analyzed in an ANOVA. Each HAp level $(0,1$, or $10 \%)$ is grouped within a week $(1,2$, or 3$)$ so that comparisons are made between treatments and within time points. A f indicates a statistically significance $\left(p_{\text {crit }}=0.05\right)$ difference from another treatment within the time point.

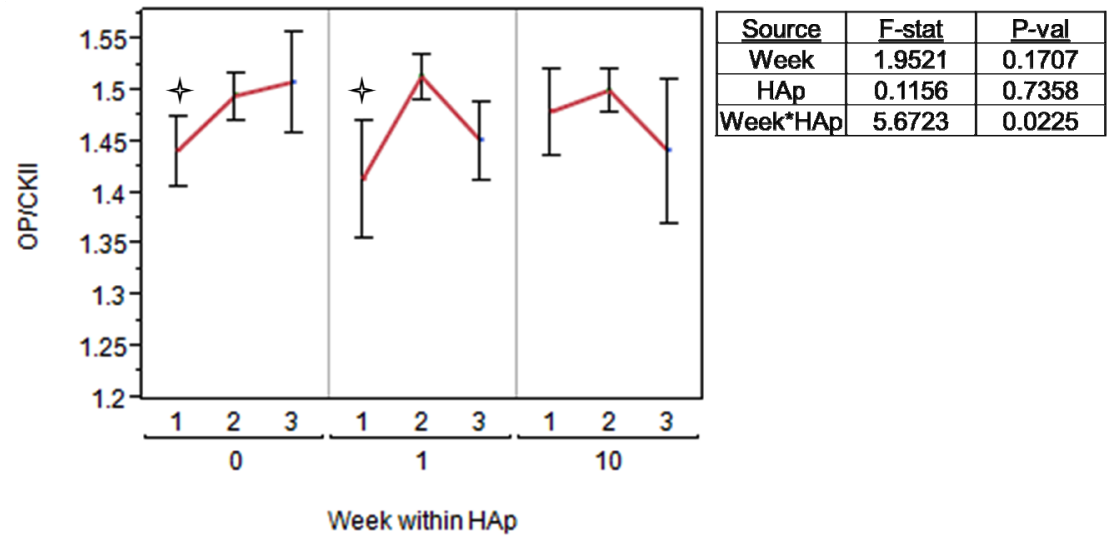

RhoA and osteocalcin were both expressed at statistically similar levels on control (0\% HAp) and mineralized (1\% or $10 \%$ HAp) scaffolds (Figure 7 ). Even within each time point, there were no significant differences measured by a t-test, which supports the observation that these genes were not significantly affected by the concentration of HAp within PCL scaffolds. RhoA is a small GTPase that is responsible for actin stress fiber formation. Recent findings have identified RhoA as not only a regulator of osteoblastogenesis [82,83], but also of mechanotransduction [84] and apoptosis specifically for osteoblasts [85]. It is important to note that RhoA is dependent on phosphorylation by GTPase Activating Proteins (GAPs) in order to become active, and then it is dephosphorylated by Guanine Nucleotide Exchange Factors (GEFs) to return to the inactive state [84]. The qPCR data does not indicate the state of phosphorylation for RhoA. However, RhoA is subject to proteosomal degradation through ubiquitination [86], and osteoblasts have been shown to completely eliminate cytosolic RhoA in as little as 18 hours [87]. Thus, the qPCR data shows that the MSCs on all three scaffolds maintained similar levels of RhoA, which suggests that mechanotransduction was not responsible for differences in osteoblast behaviors. However, this will be a behavior to investigate further in the future.

After three weeks of culture in osteogenic media, the cells were immunolabeled for either osteopontin or osteocalcin and then viewed under a fluorescence microscope. The images revealed 
presence of both bone matrix proteins on all of the scaffolds (Figure 9). Many small OC deposits were visible on the scaffold surfaces for control and mineralized scaffolds, though 10\% HAp scaffolds appeared to contain the most OC. However, for OP, there were more frequent and larger aggregates (>50 m) observed on 10\% HAp and 1\% HAp scaffolds than on HAp-free scaffolds.

Figure 9. Immunofluorescent images showing the deposition of osteocalcin (green, FITC) and osteopontin (red, TRITC) on nanofiber scaffold surfaces. Images obtained on $0 \%$ HAp (A \& B), 1\% HAp (C \& D), or 10\% HAp (E \& F) scaffolds. Magnification is $10 \times$, scale bar is $50 \mathrm{~mm}$ in all images.
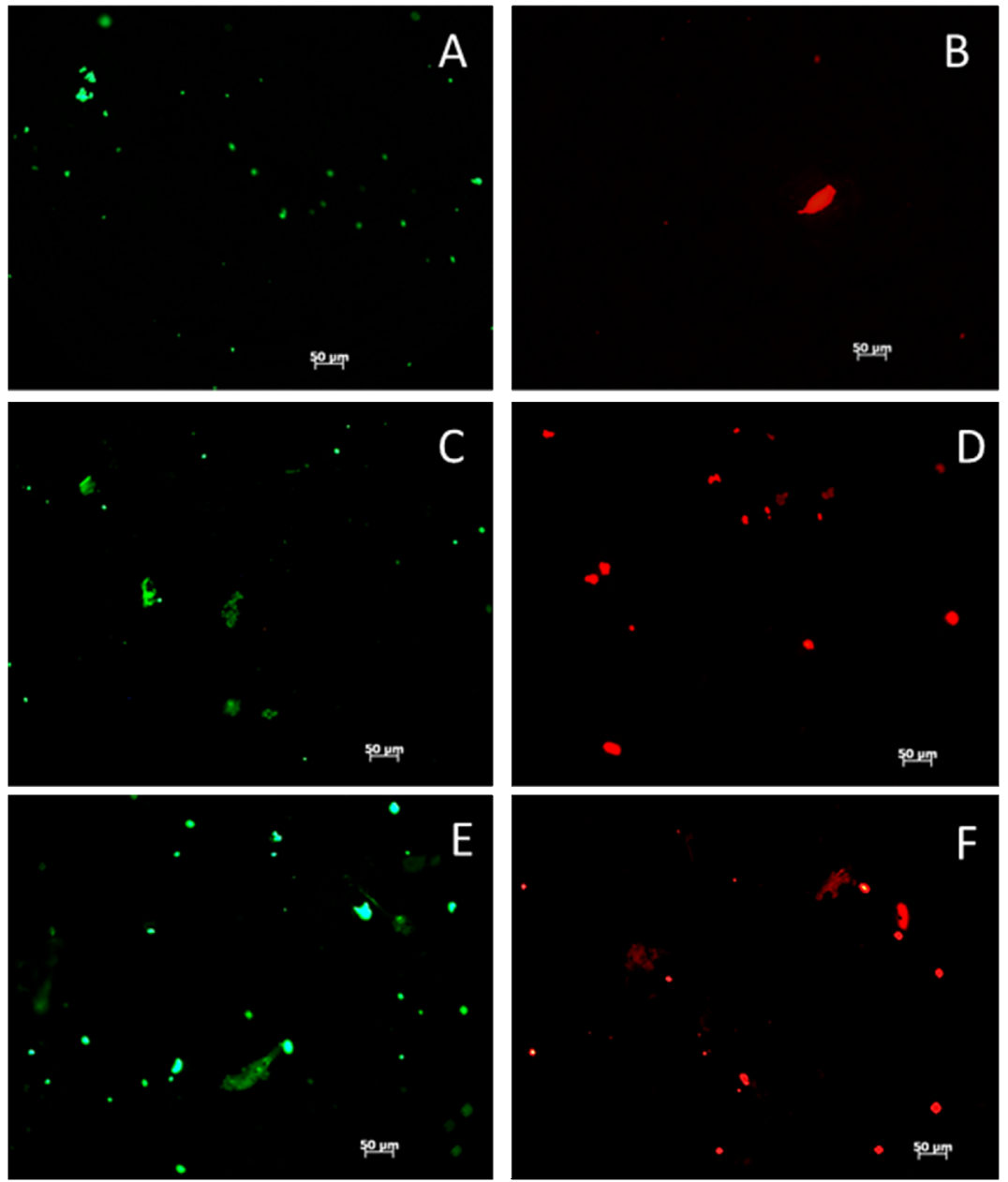

The results presented here are similar to the results from another recent study which compared electrospun nanofiber scaffolds with $0 \%, 9 \%$ or $28 \% \mathrm{w} / \mathrm{w}$ HAp nanoparticles in poly(lactic acid) (PLA). In that case, cells on $28 \%$ HAp scaffolds outperformed cells on $9 \%$ HAp scaffolds for measured ALP and osteocalcin expression measured by qPCR [18]. However, the PCR data presented within that study examined only one time point, rather than the three time points presented herein. In fact, this is the first study to report time-course gene expression data for polymer-mineral composites for bone regeneration.

The observation that MSCs are sensitive at to HAp concentrations as low as $1 \% \mathrm{w} / \mathrm{w}$ of the scaffold, and that changing between $1 \%$ and $10 \% \mathrm{w} / \mathrm{w}$ HAp content elicits different cell responses, are two important findings. The next logical and important step will be to determine the mechanism(s) by 
which MSCs sense HAp. Furthermore, these studies could examine the potential of HAp/polymer scaffolds to direct stem cell populations towards osteogenic behaviors in the absence of glucocorticoids by performing time-course cytometric population characterization to capture the differentiation of MSCs into mature phenotypes [88]. Changes in the mechanical compliance of the PCL-HAp scaffolds may occur with $10 \% \mathrm{w} / \mathrm{w}$ HAp, and compliance has been shown to be transduced through the RhoA-ROCK-MAPK pathway [84]. However, the manner with which MSCs sense changes in extracellular Ca-P mineralization is not yet clear, and this will need to be explored in the future by focusing on mechanisms by which cells sense the extracellular chemistry (mineralization) and mechanical environment.

\section{Experimental Section}

\subsection{Fabrication and Characterization of HAp/PCL Composite Nanofiber Scaffolds}

Nanofiber scaffolds were fabricated using electrospinning process. A polymer solution was prepared by dissolving of $12 \% \mathrm{w} / \mathrm{v}$ PCL (Sigma) with $3 \%$ oleic acid sodium salt in a solvent mixture of $3: 1$ chloroform and methanol (Sigma); and $0 \%, 1 \%$ and 10\% w/v of HAp nanoparticles (diameter $\leq 200 \mathrm{~nm}$, Sigma) were homogeneously mixed into this solution. A high-voltage power supply (Gamma High Voltage) applied $18-21 \mathrm{kV}$ on a blunt-tip catheter positioned $4-4.5$ " from a grounded collector. The polymer solution was fed to the catheter tip by a syringe pump (Kent Scientific) at $1.8-2.1 \mathrm{~mL} / \mathrm{h}$ and the nanofiber scaffolds were deposited on the grounded collector.

In order to examine the morphology of the nanofiber scaffolds, they were sputter-coated with $10 \mathrm{~nm}$ of gold and imaged under high magnification using a field-emission scanning electron microscope (SEM, JEOL JSM-6500F) followed by an EDX spatial elemental mapping examination. Instrument aperture and probe current were adjusted to give a dead time of $15 \%-20 \%$. Surfaces were analyzed for $5 \mathrm{~min}$ at $5-15 \mathrm{kV}$ and a magnification of $100-5000 \times$ to provide a complete profile of the different elements present. Spatial element mapping was performed by grouping pixels with similar atomic spectra. Fiber diameters were measured using SEM image analysis software. Ten measurements were made on each scaffold with $\mathrm{n}_{\min }=30$ and size distribution histogram was plotted.

Thermal characterization of the nanofiber scaffolds was performed to determine the effect of electrospinning process and HAp content on polymer crystallinity and thermal stability. Digital scanning calorimetry (DSC, TA Instruments DSC 2920) was used to determine the polymer crystallinity in different nanofiber scaffolds. The scaffolds were heated from $5{ }^{\circ} \mathrm{C}$ to $120{ }^{\circ} \mathrm{C}$ at $5{ }^{\circ} \mathrm{C} / \mathrm{min}$ and the crystallinity of a sampled was calculated by the following Equation:

$$
X_{c} \%=100 \times \frac{\Delta H_{m, \text { sample }}}{\Delta H_{m, \text { std }}}
$$

where $\mathrm{H}_{\mathrm{m} \text {,sample }}$ is the enthalpy of melting of the nanofiber scaffold and $\mathrm{H}_{\mathrm{m} \text {,std }}$ is the enthalpy of melting of $100 \%$ crystalline PCL $\left(\Delta \mathrm{H}_{\mathrm{m}, \mathrm{std}}=139 \mathrm{~J} / \mathrm{g}\right)$ [39]. Thermogravimetric analysis (TGA, TA Instruments TGA 2950) was used to measure the change in mass as a function of temperature. The nanofiber scaffolds were heated from $25{ }^{\circ} \mathrm{C}$ to $700{ }^{\circ} \mathrm{C}$ at $10{ }^{\circ} \mathrm{C} / \mathrm{min}$ and the weight loss was measured between $200{ }^{\circ} \mathrm{C}$ and $500{ }^{\circ} \mathrm{C}$. In both the thermal analysis techniques, polymer pellets that had not been subjected to electrospinning process were used as controls, and are noted as "Source PCL". 


\subsection{Rat Marrow Stromal Cell Culture}

MSCs were isolated from male Wistar rats (Rattus norvegicus) supplied by Harlan Sprague Dawley, Inc. Limbs were aseptically removed from recently euthanized animals. Soft tissue was removed and the bones were briefly stored in cold PBS before isolating cells. Metaphyseal ends of the bones were removed to expose the bone marrow cavity. In a $50 \mathrm{~mL}$ conical tube, marrow was repeatedly flushed with maintenance media ( $\alpha$-MEM with 10\% fetal bovine serum (FBS, Sigma) and $1 \%$ penicillin/streptomycin (pen/strep, Sigma)) using $10 \mathrm{~mL}$ syringes with 18 and 25 gauge needles. Media containing cells and debris was filtered with a $70 \mu \mathrm{m}$ nylon filter into a clean tube. Cells were counted using a hemocytometer before seeding. All scaffolds were sterilized by exposing them to UV light for 60 min followed while submerged in $70 \%$ ethanol. The substrates were then washed twice with warm PBS followed by warm culture media prior to MSC seeding. Cells were seeded on scaffolds in a 24-well plate at a density of 1 million per well. Cultures were incubated at $37.0{ }^{\circ} \mathrm{C}$ and $5 \% \mathrm{CO}_{2}$ for the duration of the study. Half of the media was changed at day 4. On Day 7, the media was replaced with osteogenic differentiation media ( $\alpha$-MEM with $10 \%$ fetal bovine serum, $1 \%$ penicillin-streptomycin, $10^{-8} \mathrm{M}$ Dexamethosone, $50 \mathrm{mg} / \mathrm{mL}$ ascorbic acid, $8 \mathrm{mM} \beta$-glycerolphosphate). Media was changed every 2 days for up to 3 weeks of culture. All scaffolds were cultured and assayed in triplicate at each time point specified (i.e., 1, 4, or 7 days post-seeding, and 1, 2, or 3 weeks post-differentiation, $n=6$ ).

\subsection{MSC Adhesion and Proliferation on HAp/PCL Composite Nanofiber Scaffolds}

After one, four, and seven days of culture in maintenance media, cell responses to the scaffolds were investigated through cell adhesion. Cells adhesion was investigated using the live cell stain Calcein AM (Invitrogen) (excitation: $485 \mathrm{~nm}$, emission: $530 \mathrm{~nm}$ ). Calcein AM can penetrate live cell membranes, where the AM is cleaved and the resulting calcein molecule fluoresces green. The cells were incubated in $2 \mathrm{mM}$ of Calcein AM in PBS for $45 \mathrm{~min}$ and were imaged with a fluorescence microscope (Zeiss) with appropriate filters. Images were analyzed (ImageJ, NIH) to compute the percent area covered by live cells for comparison with the cell viability assay.

Cell viability was measured after one and four days of culture (during the log phase growth) using a commercially available MTT assay kit (Sigma). Adhered cells were incubated at $37{ }^{\circ} \mathrm{C}$ for $3 \mathrm{~h}$ in a (3-[4,5-dimethylthiazol-2-yl]-2,5-diphenyl tetrazolium bromide (MTT) solution. Mitochondrial dehydrogenases of viable cells cleave the tetrazolium ring, yielding purple formazan crystals. Formazan crystals were then dissolved in the MTT solvent with 10\% (volume) Triton-X. The optical density (OD) of the solvent is proportional to the mitochondrial activity of the cells on the surface. OD was measured at $570 \mathrm{~nm}$ using a spectrophotometer (FLUOstar Omega; BMG Labtech, Durham NC). Background absorbance at $690 \mathrm{~nm}$ was subtracted from the measured absorbance.

\subsection{Osteogenic Differentiation of MSCs on HAp/PCL Composite Nanofiber Scaffolds}

MSC responses to the nanofiber scaffolds were investigated after providing the cells with osteogenic differentiation media for one, two, and three weeks. A colorimetric alkaline phosphatase (ALP) assay, total protein assay, quantitative polymerase chain reaction (qPCR), and immunofluorescent staining were used to evaluate the cell responses to nanoarchitecture containing different concentrations of HAp. 
In order to quantify intracellular ALP production after one, two, and three weeks in osteogenic conditions, the cells were lysed in CellLytic ${ }^{\circledR}$ solution (Sigma). ALP activity was measured using a commercially available colorimetric assay kit (Quantichrome ${ }^{\mathrm{TM}}$ BioAssay Systems). Briefly, ALP catalyzes the reaction removing the phosphate from $p$-nitrophenolphosphate ( $p$-NPP), thus yielding $p$-nitrophenol, and the p-nitrophenol concentration is measured by the absorbance at $405 \mathrm{~nm}$. The same lysate was also used to determine the total intracellular protein content using a commercially available BCA (bicinchoninic acid) assay (Pierce Biotechnology). The absorbance of the solution was measured using a plate reader at a wavelength of $570 \mathrm{~nm}$ and was converted to protein content using an albumin standard curve. All the ALP data was normalized with the total protein content to account for changes in number of cells present on each scaffold surface.

The expression levels of four key bone-related genes were measured with qPCR after one, two and three weeks of culture in osteogenic conditions. Messenger RNA (mRNA) was purified using an RNeasy extraction kit (Qiagen). Genomic DNA (gDNA) contamination was avoided by degrading any remaining gDNA with DNaseI (Fermentas). Complimentary DNA (cDNA) template was generated from mRNA with a first-strand synthesis kit (Fermentas), and both the DNaseI and reverse transcriptase enzymes were thermally inactivated after their respective steps according to the manufacturer's protocols. cDNA was stored in at $-80{ }^{\circ} \mathrm{C}$ until further use. For PCR reactions, primers were either designed as documented below, or were purchased as a forward-reverse primer mix (Qiagen). Casein Kinase II (CKII), Ribosomal protein L13A (RPL13A), and RhoA were measured with Qiagen primer sets, while osteopontin (OP) and collagen I (ColI) were measured with custom-designed primers (Table 1). Custom designed primers were validated by running gel electrophoresis the PCR product to ensure that the amplicon length matched the predicted length, and by performing a melt curve step at the end of real-time quantitative PCR (qPCR) to verify the presence of a single amplicon. All four genes were normalized with respect to the housekeeping gene-RPL13A expression levels.

Table 1. Custom primers used for qPCR.

\begin{tabular}{cccc}
\hline Gene & Forward primer & Reverse primer & Amplicon length \\
\hline Osteopontin & atcaggacagcaacgggaagac & gagttccaaagccagcctggaa & $224 \mathrm{bp}$ \\
Collagen I & acagaggcataaagggtcatcg & cctggcaaagatggactcaacg & $159 \mathrm{bp}$ \\
\hline
\end{tabular}

The amplicon from successful reactions was purified using the ethanol precipitation method [89]. Finally, purified amplicon concentrations were measured with a spectrophotometer (Nanodrop, Thermo Scientific), and standards were then prepared with DNase-free water for use in calculating the copy number from test $\mathrm{qPCR}$ reactions.

After three weeks in osteogenic media, the scaffolds were removed and immuno-labeled for osteopontin and osteocalcin. Cells were fixed with 3.7\% paraformaldehyde in PBS solution and permeabilized with a $1 \%$ Triton-X in PBS solution. A blocking serum of $40 \mathrm{~g} / \mathrm{mL}$ of Trypan blue (Sigma) and $100 \mathrm{~g} / \mathrm{mL}$ of bovine serum albumin in PBS was used to reduce non-specific antibody binding. After rinsing and blocking, the scaffolds were incubated in either an osteopontin primary antibody (1:100 in PBS, V-19 purified goat polyclonal antibody of mouse origin, Santa Cruz Biotechnology) or an osteocalcin primary antibody (P-18 purified goat polyclonal antibody of mouse 
origin, Santa Cruz Biotechnology) for one hour. After an additional blocking step and PBS wash, the scaffolds were then incubated in a FITC-conjugated or TRITC-conjugated secondary antibody (1:200 donkey anti-goat IgG, Santa Cruz Biotechnology) for $45 \mathrm{~min}$ in the dark. The scaffolds were rinsed once more before being imaged under $470 \mathrm{~nm}$ excitation wavelength using a fluorescence microscope (Zeiss).

\subsection{Statistical Analysis}

All test and control substrates were cultured and assayed in triplicate at each time point specified. The experiments were conducted in duplicate using different animals as the MSC source for each study. All the statistics presented here as a mean $+/-$ standard deviation. A one-way ANOVA with a Tukey adjustment for multiple comparisons was used to determine the effects of treatment (HAp concentration), time (days or weeks where noted), and the interaction of treatment by time (Hap*time). Any effect (HAp, time, or Hap*time) with a p-value less than 0.05 was considered significant and for borderline significant values of $0.05<\mathrm{p}<0.1$ the result was simply noted. Additionally, assay values at each time point were compared using a two-way t-test and significant $\mathrm{p}$-values $(\mathrm{p} \leq 0.05)$ were noted with a star on the corresponding chart.

\section{Conclusions}

PCL nanofiber scaffolds were fabricated to be HAp-free ( $0 \%$ HAp, control), or have either $1 \%$ or $10 \%$ HAp nanoparticles within the PCL nanofibers. Material characterization methods verified that the desired nanofibrous morphology and compositions were achieved, and a difference in mean fiber diameter was unlikely to significantly affect the cell population. There were difference in the initial levels of metabolic activity, but by day seven, the cell populations, as measured by coverage, were very similar. Once in osteogenic media, ALP activity showed consistencies with previous reports by having elevated levels on 10\% HAp scaffolds at the third week. Using qPCR, expression levels for three key genes were measured to be differentially regulated as a result of HAp nanoparticles in a concentration-dependent manner. This was the first study to present time-course qPCR data for key osteoblast-related genes and the information demonstrated high sensitivity to HAp nanoparticles. Future studies will investigate activation for RhoA and CKII as well as potential mechanisms sensing the extracellular chemistry and mechanical environment.

\section{Acknowledgements}

Funding support for this work was provided by the National Science Foundation (CBET-0827827) and the Colorado Office of Economic Development and International Trade.

\section{References}

1. Drosse, I.; Volkmer, E.; Capanna, R.; de Biase, P.; Mutschler, W.; Schieker, M. Tissue engineering for bone defect healing: an update on a multi-component approach. Injury 2008, 39, 9-20.

2. Heino, T.J.; Hentunen, T.A. Differentiation of osteoblasts and osteocytes from mesenchymal stem cells. Curr. Stem. Cell Res. Ther. 2008, 3, 131-145. 
3. Haynesworth, S.E.; Goshima, J.; Goldberg, V.M.; Caplan, A.L. Characterization of cells with osteogenic potential from human marrow. Bone 1992, 13, 81-88.

4. Prockop, D. Marrow stromal cells as stem cells for nonhematopoietic tissues. Science 1997, 276, 71-74.

5. Jorgensen, N.R.; Henriksen, Z.; Sorensen, O.H.; Civitelli, R. Dexamethasone, BMP-2, and 1,25-dihydroxyvitamin D enhance a more differentiated osteoblast phenotype: Validation of an in vitro model for human bone marrow-derived primary osteoblasts. Steroids 2004, 69, 219-226.

6. Johnson, M.R.; Lee, H.J.; Bellamkonda, R.V.; Guldberg, R.E. Sustained release of BMP-2 in a lipid-based microtube vehicle. Acta Biomater. 2009, 5, 23-28.

7. Laflamme, C.; Rouabhia, M. Effect of BMP-2 and BMP-7 homodimers and a mixture of BMP-2/BMP-7 homodimers on osteoblast adhesion and growth following culture on a collagen scaffold. Biomed. Mater. 2008, 3, doi:10.1088/1748-6041/3/1/015008.

8. Laurencin, C.T.; Attawia, M.A.; Lu, L.Q.; Borden, M.D.; Lu, H.H.; Gorum, W.J.; Lieberman, J.R. Poly(lactide-co-glycolide)/hydroxyapatite delivery of BMP-2-producing cells: A regional gene therapy approach to bone regeneration. Biomaterials 2001, 22, 1271-1277.

9. Lee, J.Y.; Choo, J.E.; Choi, Y.S.; Suh, J.S.; Lee, S.J.; Chung, C.P.; Park, Y.J. Osteoblastic differentiation of human bone marrow stromal cells in self-assembled BMP-2 receptor-binding peptide-amphiphiles. Biomaterials 2009, 30, 3532-3541.

10. Olivares-Navarrete, R.; Raz, P.; Zhao, G.; Chen, J.; Wieland, M.; Cochran, D.L.; Chaudhri, R.A.; Ornoy, A.; Boyan, B.D.; Schwartz, Z. Integrin alpha2beta1 plays a critical role in osteoblast response to micron-scale surface structure and surface energy of titanium substrates. Proc. Natl. Acad. Sci. USA 2008, 105, 15767-15772.

11. Marletta, G.; Ciapetti, G.; Satriano, C.; Pagani, S.; Baldini, N. The effect of irradiation modification and RGD sequence adsorption on the response of human osteoblasts to polycaprolactone. Biomaterials 2005, 26, 4793-4804.

12. Dalby, M.J.; Gadegaard, N.; Tare, R.; Andar, A.; Riehle, M.O.; Herzyk, P.; Wilkinson, C.D.; Oreffo, R.O. The control of human mesenchymal cell differentiation using nanoscale symmetry and disorder. Nat. Mater. 2007, 6, 997-1003.

13. Biggs, M.J.; Richards, R.G.; Gadegaard, N.; Wilkinson, C.D.; Oreffo, R.O.; Dalby, M.J. The use of nanoscale topography to modulate the dynamics of adhesion formation in primary osteoblasts and ERK/MAPK signalling in STRO-1+ enriched skeletal stem cells. Biomaterials 2009, 30, 5094-5103.

14. Olivares-Navarrete, R.; Hyzy, S.L.; Hutton, D.L.; Erdman, C.P.; Wieland, M.; Boyan, B.D.; Schwartz, Z. Direct and indirect effects of microstructured titanium substrates on the induction of mesenchymal stem cell differentiation towards the osteoblast lineage. Biomaterials 2010, 31, $2728-2735$.

15. Ruckh, T.T.; Kumar, K.; Kipper, M.J.; Popat, K.C. Osteogenic differentiation of bone marrow stromal cells on poly(epsilon-caprolactone) nanofiber scaffolds. Acta Biomater. 2010.

16. Wutticharoenmongkol, P.; Pavasant, P.; Supaphol, P. Osteoblastic phenotype expression of MC3T3-E1 cultured on electrospun polycaprolactone fiber mats filled with hydroxyapatite nanoparticles. Biomacromolecules 2007, 8, 2602-2610. 
17. Zhang, P.; Hong, Z.; Yu, T.; Chen, X.; Jing, X. In vivo mineralization and osteogenesis of nanocomposite scaffold of poly(lactide-co-glycolide) and hydroxyapatite surface-grafted with poly(1-lactide). Biomaterials 2008.

18. Lee, J.H.; Rim, N.G.; Jung, H.S.; Shin, H. Control of osteogenic differentiation and mineralization of human mesenchymal stem cells on composite nanofibers containing poly[lactic-co-(glycolic acid)] and hydroxyapatite. Macromol. Biosci. 2010, 10, 173-182.

19. Gupta, D.; Venugopal, J.; Mitra, S.; Giri Dev, V.R.; Ramakrishna, S. Nanostructured biocomposite substrates by electrospinning and electrospraying for the mineralization of osteoblasts. Biomaterials 2009, 30, 2085-2094.

20. Ramakrishna, S.; Fujihara, K.; Teo, W.-E.; Lim, T.-C.; Ma, Z. An Introduction to Electrospinning and Nanofibers; World Scientific: Singapore, 2005; p. 382.

21. Rutledge, G.C.; Fridrikh, S.V. Formation of fibers by electrospinning. Adv. Drug Deliv. Rev. 2007, 59, 1384-1391.

22. Theron, S.A.; Zussman, E.; Yarin, A.L. Experimental investigation of the governing parameters in the electrospinning of polymer solutions. Polymer 2004, 45, 2017-2030.

23. Sinha, V.R.; Bansal, K.; Kaushik, R.; Kumria, R.; Trehan, A. Poly-e-caprolactone microspheres and nanospheres: An overview. Int. J. Pharm. 2004, 278, 1-23.

24. Zeng, J.; Xu, X.; Chen, X.; Liang, Q.; Bian, X.; Yang, L.; Jing, X. Biodegradable electrospun fibers for drug delivery. J. Control. Release 2003, 92, 227-231.

25. Pulkkinen, M.; Malin, M.; Tarvainen, T.; Saarimäki, T.; Seppälä, J.; Järvinen, K. Effects of block length on the enzymatic degradation and erosion of oxazoline linked poly-e-caprolactone. Eur. J. Pharm. Sci. 2007, 31, 119-128.

26. Sangsanoh, P.; Waleetorncheepsawat, S.; Suwantong, O.; Wutticharoenmongkol, P.; Weeranantanapan, O.; Chuenjitbuntaworn, B.; Cheepsunthorn, P.; Pavasant, P.; Supaphol, P. In vitro biocompatibility of schwann cells on surfaces of biocompatible polymeric electrospun fibrous and solution-cast film scaffolds. Biomacromolecules 2007, 8, 1587-1594.

27. Palmer, L.C.; Newcomb, C.J.; Kaltz, S.R.; Spoerke, E.D.; Stupp, S.I. Biomimetic systems for hydroxyapatite mineralization inspired by bone and enamel. Chem. Rev. 2008, 108, 4754-4783.

28. Anderson, H.C.; Sipe, J.B.; Hessle, L.; Dhanyamraju, R.; Atti, E.; Camacho, N.P.; Millan, J.L. Impaired calcification around matrix vesicles of growth plate and bone in alkaline phosphatase-deficient mice. Am. J. Pathol. 2004, 164, 841-847.

29. Genge, B.R.; Wu, L.N.; Wuthier, R.E. In vitro modeling of matrix vesicle nucleation: Synergistic stimulation of mineral formation by annexin A5 and phosphatidylserine. J. Biol. Chem. 2007, 282, 26035-26045.

30. Nikolov, S.; Raabe, D. Hierarchical modeling of the elastic properties of bone at submicron scales: The role of extrafibrillar mineralization. Biophys. J. 2008, 94, 4220-4232.

31. Norman, J.; Shapter, J.G.; Short, K.; Smith, L.J.; Fazzalari, N.L. Micromechanical properties of human trabecular bone: A hierarchical investigation using nanoindentation. J. Biomed. Mater. Res. A 2008, 87, 196-202.

32. McCreadie, B.R.; Goulet, R.W.; Feldkamp, L.A.; Goldstein, S.A. Hierarchical structure of bone and micro-computed tomography. Adv. Exp. Med. Biol. 2001, 496, 67-83. 
33. White, D.J.; Puranen, S.; Johnson, M.S.; Heino, J. The collagen receptor subfamily of the integrins. Int. J. Biochem. Cell Biol. 2004, 36, 1405-1410.

34. Denhardt, D.T.; Noda, M. Osteopontin expression and function: Role in bone remodeling. J. Cell Biochem. Suppl. 1998, 30-31, 92-102.

35. Kazanecki, C.C.; Uzwiak, D.J.; Denhardt, D.T. Control of osteopontin signaling and function by post-translational phosphorylation and protein folding. J. Cell Biochem. 2007, 102, 912-924.

36. McKee, M.D.; Nanci, A. Osteopontin: An interfacial extracellular matrix protein in mineralized tissues. Connect. Tissue Res. 1996, 35, 197-205.

37. Cui, W.; al, e. In situ growth of hydroxyapatite within electrospun poly(DL-lactide) fibers. J. Biomed. Mater. Res. Part A 2007, 82, 831-841.

38. Fang, B.; Wan, Y.Z.; Tang, T.T.; Gao, C.; Dai, K.R. Proliferation and osteoblastic differentiation of human bone marrow stromal cells on hydroxyapatite/bacterial cellulose nanocomposite scaffolds. Tissue Eng. Part A 2009, 15, 1091-1098.

39. Guarino, V.; Taddei, P.; Di Foggia, M.; Fagnano, C.; Ciapetti, G.; Ambrosio, L. The influence of hydroxyapatite particles on in vitro degradation behaviour of pcl based composite scaffolds. Tissue Eng. Part A 2009, 15, 3655-3668.

40. Mei, F.; Zhong, J.; Yang, X.; Ouyang, X.; Zhang, S.; Hu, X.; Ma, Q.; Lu, J.; Ryu, S.; Deng, X. Improved biological characteristics of poly(L-lactic acid) electrospun membrane by incorporation of multiwalled carbon nanotubes/hydroxyapatite nanoparticles. Biomacromolecules 2007, 8, 3729-3735.

41. Venugopal, J.R.; Low, S.; Choon, A.T.; Kumar, A.B.; Ramakrishna, S. Nanobioengineered electrospun composite nanofibers and osteoblasts for bone regeneration. Artif Organs 2008, 32, 388-397.

42. Kim, H.-W.; Lee, H.-H.; Knowles, J.C. Electrospinning biomedical nanocomposite fibers of hydroxyapaite/poly(lactic acid) for bone regeneration. J. Biomed. Mater. Res. Part A 2006, 79, 643-649.

43. Jackson, S.M.; Demer, L.L. Peroxisome proliferator-activated receptor activators modulate the osteoblastic maturation of MC3T3-E1 preosteoblasts. FEBS Lett. 2000, 471, 119-124.

44. Still, K.; Grabowski, P.; Mackie, I.; Perry, M.; Bishop, N. The peroxisome proliferator activator receptor alpha/delta agonists linoleic acid and bezafibrate upregulate osteoblast differentiation and induce periosteal bone formation in vivo. Calcif. Tissue Int. 2008, 83, 285-292.

45. Xu, H.E.; Lambert, M.H.; Montana, V.G.; Parks, D.J.; Blanchard, S.G.; Brown, P.J.; Sternbach, D.D.; Lehmann, J.M.; Wisely, G.B.; Willson, T.M.; Kliewer, S.A.; Milburn, M.V. Molecular recognition of fatty acids by peroxisome proliferator-activated receptors. Mol. Cell1999, 3, 397-403.

46. Berger, J.; Moller, D. The mechanisms of action of PPARs. Annu. Rev. Med. 2002, 53, 409-435.

47. Lecka-Czernik, B.; Suva, L.J. Resolving the two "bony" faces of PPAR-gamma. PPAR Res. 2006, doi:10.1155/PPAR/2006/27489.

48. Lin, T.-H.; Yang, R.-S.; Tang, C.-H.; Lin, C.-P.; Fu, W.-M. PPARg inhibits osteogenesis via the down-regulation of the expression of COX-2 and iNOS in rats. Bone 2007, 41, 562-574.

49. Syversen, U.; Bakke, I.; Aune, G.; Thommesen, L. PPAR-Alpha agonists increase bone mineral density in female rats. J. Bone Miner. Res. 2003, 18, S2-S56. 
50. De Jong, D.S.; Vaes, B.L.; Dechering, K.J.; Feijen, A.; Hendriks, J.M.; Wehrens, R.; Mummery, C.L.; van Zoelen, E.J.; Olijve, W.; Steegenga, W.T. Identification of novel regulators associated with early-phase osteoblast differentiation. J. Bone Miner. Res. 2004, 19, 947-958.

51. Badami, A.S.; Kreke, M.R.; Thompson, M.S.; Riffle, J.S.; Goldstein, A.S. Effect of fiber diameter on spreading, proliferation, and differentiation of osteoblastic cells on electrospun poly(lactic acid) substrates. Biomaterials 2006, 27, 596-606.

52. Bashur, C.A.; Dahlgren, L.A.; Goldstein, A.S. Effect of fiber diameter and orientation on fibroblast morphology and proliferation on electrospun poly(D,L-lactic-co-glycolic acid) meshes. Biomaterials 2006, 27, 5681-5688.

53. Tsiridis, E.; Upadhyay, N.; Giannoudis, P. Molecular aspects of fracture healing: Which are the important molecules? Injury 2007, 38, 11-25.

54. Chen, L.; Jiang, W.; Huang, J.; He, B.C.; Zuo, G.W.; Zhang, W.; Luo, Q.; Shi, Q.; Zhang, B.Q.; Wagner, E.R.; et al. Insulin-like growth factor 2 (IGF2) potentiates BMP9-induced osteogenic differentiation and bone formation. J. Bone Miner. Res. 2010, 25, 2447-2459.

55. Sundelacruz, S.; Kaplan, D.L. Stem cell- and scaffold-based tissue engineering approaches to osteochondral regenerative medicine. Semin. Cell Dev. Biol. 2009, 20, 646-655.

56. Ekholm, E.C.; Ravanti, L.; Kahari, V.; Paavolainen, P.; Penttinen, R.P. Expression of extracellular matrix genes: transforming growth factor (TGF)-betal and ras in tibial fracture healing of lathyritic rats. Bone 2000, 27, 551-557.

57. Hirakawa, K.; Hirota, S.; Ikeda, T.; Yamaguchi, A.; Takemura, T.; Nagoshi, J.; Yoshiki, S.; Suda, T.; Kitamura, Y.; Nomura, S. Localization of the mRNA for bone matrix proteins during fracture healing as determined by in situ hybridization. J. Bone Miner. Res. 1994, 9, 1551-1557.

58. Schuckert, K.H.; Jopp, S.; Teoh, S.H. Mandibular defect reconstruction using three-dimensional polycaprolactone scaffold in combination with platelet-rich plasma and recombinant human bone morphogenetic protein-2: De novo synthesis of bone in a single case. Tissue Eng. Part A 2009, 15, 493-499.

59. Thorwarth, M.; Rupprecht, S.; Falk, S.; Felszeghy, E.; Wiltfang, J.; Schlegel, K.A. Expression of bone matrix proteins during de novo bone formation using a bovine collagen and platelet-rich plasma (prp) — an immunohistochemical analysis. Biomaterials 2005, 26, 2575-2584.

60. Kosaki, N.; Takaishi, H.; Kamekura, S.; Kimura, T.; Okada, Y.; Minqi, L.; Amizuka, N.; Chung, U.I.; Nakamura, K.; Kawaguchi, H.; et al. Impaired bone fracture healing in matrix metalloproteinase-13 deficient mice. Biochem. Biophys. Res. Commun. 2007, 354, 846-851.

61. Weiss, S.; Zimmermann, G.; Baumgart, R.; Kasten, P.; Bidlingmaier, M.; Henle, P. Systemic regulation of angiogenesis and matrix degradation in bone regeneration-distraction osteogenesis compared to rigid fracture healing. Bone 2005, 37, 781-790.

62. Henle, P.; Zimmermann, G.; Weiss, S. Matrix metalloproteinases and failed fracture healing. Bone 2005, 37, 791-798.

63. Coleman, J.E. Structure and mechanism of alkaline phosphatase. Annu. Rev. Biophys. Biomol. Struct. 1992, 21, 441-483.

64. Orimo, H.; Shimada, T. The role of tissue-nonspecific alkaline phosphatase in the phosphate-induced activation of alkaline phosphatase and mineralization in SaOS-2 human osteoblast-like cells. Mol. Cell. Biochem. 2008, 315, 51-60. 
65. Kulterer, B.; Friedl, G.; Jandrositz, A.; Sanchez-Cabo, F.; Prokesch, A.; Paar, C.; Scheideler, M.; Windhager, R.; Preisegger, K.H.; Trajanoski, Z. Gene expression profiling of human mesenchymal stem cells derived from bone marrow during expansion and osteoblast differentiation. BMC Genomics. 2007, 8, doi:10.1186/1471-2164-8-70.

66. Park, S.-H.; Kim, T.-L.; Ku, Y.; Chung, C.-P.; Han, S.-B.; Yu, J.-H.; Lee, S.-P.; Kim, H.-W.; Lee, H.-H. Effect of hydroxyapatite-coated nanofibrous membrane on the responses of human periodontal ligament fibroblast. J. Ceram. Soc. Jpn. 2008, 116, 31-35.

67. Venugopal, J.; Low, S.; Choon, A.; Kumar, A.; Ramakrishna, S. Electrospun-modified nanofibrous scaffolds for the mineralization of osteoblast cells. J. Biomed. Mater. Res. Part A 2007, 85, 408-417.

68. Salih, E.; Ashkar, S.; Gerstenfeld, L.C.; Glimcher, M.J. Protein kinases of cultured osteoblasts: Selectivity for the extracellular matrix proteins of bone and their catalytic competence for osteopontin. J. Bone Miner. Res. 1996, 11, 1461-1473.

69. Katayama, Y.; House, C.M.; Udagawa, N.; Kazama, J.J.; McFarland, R.J.; Martin, T.J.; Findlay, D.M. Casein kinase 2 phosphorylation of recombinant rat osteopontin enhances adhesion of osteoclasts but not osteoblasts. J. Cell Physiol. 1998, 176, 179-187.

70. Wang, J.; Glimcher, M.J.; Mah, J.; Zhou, H.Y.; Salih, E. Expression of bone microsomal casein kinase II, bone sialoprotein, and osteopontin during the repair of calvarial defects. Bone 1998, 22, $621-628$.

71. Liu, F.; Malaval, L.; Aubin, J.E. Global amplification polymerase chain reaction reveals novel transitional stages during osteoprogenitor differentiation. J. Cell Sci. 2003, 116, 1787-1796.

72. Hamada, K.; Hirose, M.; Yamashita, T.; Ohgushi, H. Spatial distribution of mineralized bone matrix produced by marrow mesenchymal stem cells in self-assembling peptide hydrogel scaffold. J. Biomed. Mater. Res. A 2008, 84, 128-136.

73. Robey, P.G.; Fedarko, N.S.; Hefferan, T.E.; Bianco, P.; Vetter, U.K.; Grzesik, W.; Friedenstein, A.; van der Pluijm, G.; Mintz, K.P.; Young, M.F.; et al. Structure and molecular regulation of bone matrix proteins. J. Bone Miner. Res. 1993, 8, 483-487.

74. Young, M.F. Bone matrix proteins: Their function, regulation, and relationship to osteoporosis. Osteoporos. Int. 2003, 14, 35-42.

75. Qin, C.; Baba, O.; Butler, W.T. Post-translational modifications of sibling proteins and their roles in osteogenesis and dentinogenesis. Crit. Rev. Oral Biol. Med. 2004, 15, 126-136.

76. Keykhosravani, M.; Doherty-Kirby, A.; Zhang, C.; Brewer, D.; Goldberg, H.A.; Hunter, G.K.; Lajoie, G. Comprehensive identification of post-translational modifications of rat bone osteopontin by mass spectrometry. Biochemistry 2005, 44, 6990-7003.

77. Goldberg, H.A.; Hunter, G.K. The inhibitory activity of osteopontin on hydroxyapatite formation in vitro. Ann. NY. Acad. Sci. 1995, 760, 305-308.

78. Pampena, D.A.; Robertson, K.A.; Litvinova, O.; Lajoie, G.; Goldberg, H.A.; Hunter, G.K. Inhibition of hydroxyapatite formation by osteopontin phosphopeptides. Biochem. J. 2004, 378, 1083-1087.

79. Rajachar, R.M.; Truong, A.Q.; Giachelli, C.M. The influence of surface mineral and osteopontin on the formation and function of murine bone marrow-derived osteoclasts. J. Mater. Sci. Mater. Med. 2008, 19, 3279-3285. 
80. Sodek, J.; Zhu, B.; Huynh, M.H.; Brown, T.J.; Ringuette, M. Novel functions of the matricellular proteins osteopontin and osteonectin/SPARC. Connect. Tissue Res. 2002, 43, 308-319.

81. Taller, A.; Grohe, B.; Rogers, K.A.; Goldberg, H.A.; Hunter, G.K. Specific adsorption of osteopontin and synthetic polypeptides to calcium oxalate monohydrate crystals. Biophys. J. 2007, 93, 1768-1777.

82. McBeath, R.; Pirone, D.M.; Nelson, C.M.; Bhadriraju, K.; Chen, C.S. Cell shape, cytoskeletal tension, and RhoA regulate stem cell lineage commitment. Dev. Cell 2004, 6, 483-495.

83. Meyers, V.E.; Zayzafoon, M.; Douglas, J.T.; McDonald, J.M. RhoA and cytoskeletal disruption mediate reduced osteoblastogenesis and enhanced adipogenesis of human mesenchymal stem cells in modeled microgravity. J. Bone Miner. Res. 2005, 20, 1858-1866.

84. Khatiwala, C.B.; Kim, P.D.; Peyton, S.R.; Putnam, A.J. ECM compliance regulates osteogenesis by influencing MAPK signaling downstream of RhoA and ROCK. J. Bone Miner. Res. 2009, 24, 886-898.

85. Yoshida, T.; Clark, M.F.; Stern, P.H. The small GTPase RhoA is crucial for MC3T3-E1 osteoblastic cell survival. J. Cell Biochem. 2009, 106, 896-902.

86. Chan, M.C.; Nguyen, P.H.; Davis, B.N.; Ohoka, N.; Hayashi, H.; Du, K.; Lagna, G.; Hata, A. A novel regulatory mechanism of the bone morphogenetic protein (BMP) signaling pathway involving the carboxyl-terminal tail domain of BMP type II receptor. Mol. Cell. Biol. 2007, 27, 5776-5789.

87. Zambuzzi, W.F.; Bruni-Cardoso, A.; Granjeiro, J.M.; Peppelenbosch, M.P.; de Carvalho, H.F.; Aoyama, H.; Ferreira, C.V. On the road to understanding of the osteoblast adhesion: Cytoskeleton organization is rearranged by distinct signaling pathways. J. Cell Biochem. 2009, 108, 134-144.

88. Robling, A.G.; Castillo, A.B.; Turner, C.H. Biomechanical and molecular regulation of bone remodeling. Annu. Rev. Biomed. Eng. 2006, 8, 455-498.

89. Fregel, R.; Gonzalez, A.; Cabrera, V.M. Improved ethanol precipitation of DNA. Electrophoresis 2010, 31, 1350-1352.

(C) 2012 by the authors; licensee MDPI, Basel, Switzerland. This article is an open access article distributed under the terms and conditions of the Creative Commons Attribution license (http://creativecommons.org/licenses/by/3.0/). 